\title{
Resección en cuña bilateral en paciente con astigmatismo alto residual posqueratoplastia penetrante: Reporte de caso
}

\section{Bilateral corneal wedge resection in a patient with high residual astigmatism after penetrating keratoplasty: A case report}

\author{
Cesar Hernández-Chavarría ${ }^{1 *}$, Ricardo Navarro-Saucedo y Héctor G. Cámara-Castillo ${ }^{2,3}$
}

${ }^{1}$ Departamento de Oftalmología, Hospital General Regional \# 12 Benito Juárez García, Mérida, Yucatán; ${ }^{2}$ Clínica de Mérida S.A. de C.V., Mérida, Yucatán; ${ }^{3}$ Departamento de Oftalmología, Hospital para Evitar la Ceguera en México, Ciudad de México. México

\section{Resumen}

Objetivo: Reportar un caso con astigmatismo alto residual posterior a queratoplastia penetrante tratado con resección en cuña corneal. Observaciones: Reportamos nuestra experiencia con un paciente tratado con resección en cuña por astigmatismo residual posterior a queratoplastia penetrante. Se retiró una cuña delgada de tejido corneal justo por dentro de la interface donador-receptor. La cuña se inició en el eje más plano queratométrico y se extendió 20 grados a cada lado. Se realizó el mismo procedimiento en el eje plano contralateral. La herida se cerró con nylon 10-0. Reportamos la topografía pre y posquirúrgica. Resultado: El paciente contaba con astigmatismo preoperatorio de 15 dioptrías (D) queratométricas. El astigmatismo posquirúrgico después de la resección en cuña corneal fue de 1.7 D queratométricas, con reducción de 13.3 D queratométricas. Conclusiones: La resección en cuña es una opción efectiva para tratamiento de astigmatismos residuales altos posqueratoplastia penetrante cuando no es candidato a otros procedimientos conservadores.

Palabras clave: Cornea. Astigmatismo. Queratoplastía. Injertos. Tratamiento. Topografía corneal.

\section{Abstract}

Purpose: To report a case of high astigmatism after penetrating keratoplasty treated with corneal wedge resection. Observations: We report our experience with a patient treated with corneal wedge excision for high astigmatism. A thin wedge of corneal tissue was removed from the donor-recipient interface. The wedge started on the flattest axis by keratometry and extended 20 degrees on each side; the same procedure was performed on the contralateral flat axis. The wound was closed with 10-0 nylon. We report the pre and post-operative topography. Results: The mean preoperative astigmatism by keratometry was 15 diopters (D). After wedge resection, the mean astigmatism was 1.7 D. The mean reduction in astigmatism by keratometry was of 13.3 D. Conclusion: Corneal wedge resection is a good option for high residual astigmatism after penetrating keratoplasty when the patient is not a candidate for other conservative treatments.

Key words: Cornea. Astigmatism. Keratoplasty. Grafts. Treatment. Corneal topography.

\section{Correspondencia:}

*Cesar Hernández-Chavarría

Av. Cumbres de Maltrata, 423

Col. Narvarte Poniente

Fecha de recepción: 19-03-2018

Fecha de aceptación: 11-09-2018

E-mail: cesar.hernandez.chavarria @gmail.com

0187-4519/@ 2018 Sociedad Mexicana de Oftalmolo (http://creativecommons.org/licenses/by-nc-nd/4.0/).
Disponible en internet: 03-07-2019 Rev Mex Oftalmol. 2020;94(2):90-93 www.rmo.com.mx DOI: 10.24875/RMO.M19000070 
La queratoplastia penetrante ha demostrado que es un tratamiento efectivo para una variedad de condiciones corneales. Sin embargo, la rehabilitación visual posterior a queratoplastia penetrante sigue siendo un reto. Una buena agudeza visual puede no ser obtenida por un astigmatismo alto residual a pesar de un botón corneal transparente. La prevalencia de un astigmatismo postoperatorio residual a largo plazo es de $>5$ dioptrías (D) hasta en el $31 \%{ }^{1}$. Un botón corneal claro con alto astigmatismo es interpretado por el paciente como un mal resultado, especialmente cuando el ojo contralateral tiene buena visión o un pequeño o nulo error refractivo. El astigmatismo alto puede manejarse con lentes aéreos 0 lentes de contacto o con intervención quirúrgica. La resección en cuña comprende la resección de una cuña corneal por dentro o por fuera de la interface donador-receptor en el eje más plano para aumentar su curvatura ${ }^{1}$. Reportamos nuestra experiencia con un paciente tratado con resección en cuña por astigmatismo residual alto posqueratoplastia penetrante por queratocono. También reportamos su topografía pre y posquirúrgica.

\section{Reporte del caso}

Paciente masculino de 34 años sometido a una queratoplastia penetrante en el ojo izquierdo por queratocono. Con un astigmatismo regular, oblicuo con un moño simétrico y ortogonal queratométrico residual de $15 \mathrm{D}$ (Fig. 1) después de retirar suturas a los 10 meses de la operación. La agudeza visual estaba en cuenta dedos y no mejoraba con lente aéreo ni toleraba lente de contacto. Se realizó una resección en cuña al año de la queratoplastia penetrante.

Técnica quirúrgica: Se extrajo una cuña delgada de la córnea, de $0.75 \mathrm{~mm}$ de grosor, justo por dentro de la interface donador-receptor, según el nomograma de Troutman, el cual establece que para una corrección de 10 dioptrías es necesaria una cuña de $0.5 \mathrm{~mm}$ y por cada dioptría extra de corrección se requieren añadir $0.05 \mathrm{~mm}^{1}$. Se realizó el marcado de la zona más plana de la córnea basado en el mapa de superficie de la topografía, se realizó un corte del $80 \%$ de espesor corneal basándose en la paquimetría por ultrasonido, extendiéndose 20 grados a cada lado del eje de los 30 grados (meridiano más plano) a $0.75 \mathrm{~mm}$ por dentro de la interface. Se realizó la separación de la interface donador-receptor correspondiente a la longitud de la incisión previa. Se retiró la cuña de tejido

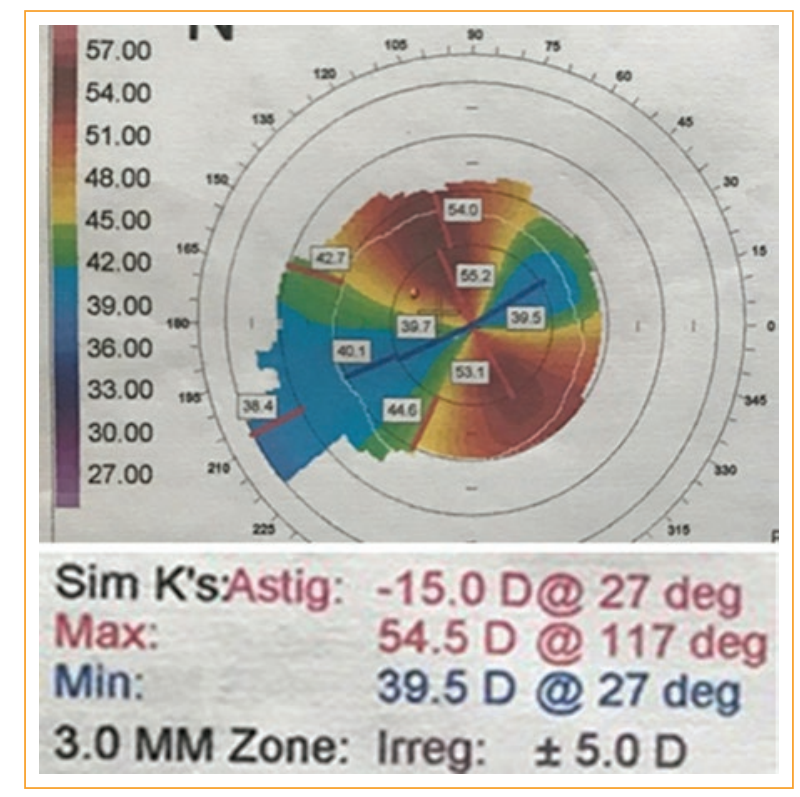

Figure 1. Topografía pre-quirúrgica.

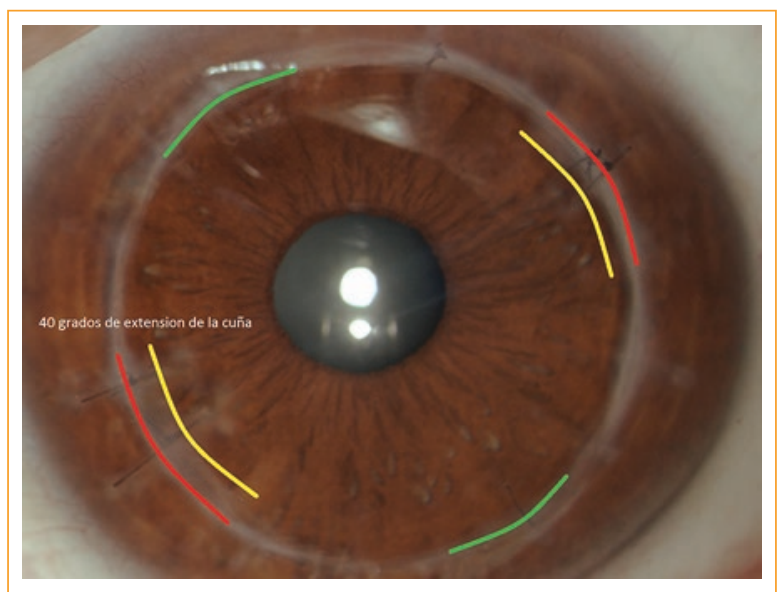

Figure 2. Líneas rojas, incisión en la interface. Líneas amarillas, incisivos $0.75 \mathrm{~mm}$ de la interface en botón corneal. Líneas verdes, incisión relajante.

corneal y se colocaron 5 puntos simples de nylon 10-0. Se realizó el mismo procedimiento a 180 grados en el eje de 210 grados (eje más plano opuesto). También se realizaron incisiones relajantes en la interface a 120 (eje más curvo), extendiéndose 20 grados a cada lado, de $80 \%$ de grosor corneal. Basándose en la paquimetría por ultrasonido se realizó el mismo procedimiento a 180 grados en el eje de 300 grados (eje más curvo opuesto).

\section{Resultado}

Al año de seguimiento, el paciente presentaba botón corneal transparente, agudeza visual mejor corregida 
Table 1. Cambios refractivos

\begin{tabular}{|l|c|c|}
\hline Resultados & Prequirúrgico & Posquirúrgico \\
\hline Astigmatismo queratométrico & $15 \mathrm{D}$ & $1.7 \mathrm{D}$ \\
\hline Agudeza visual & Cuenta dedos & $20 / 40$ \\
\hline
\end{tabular}

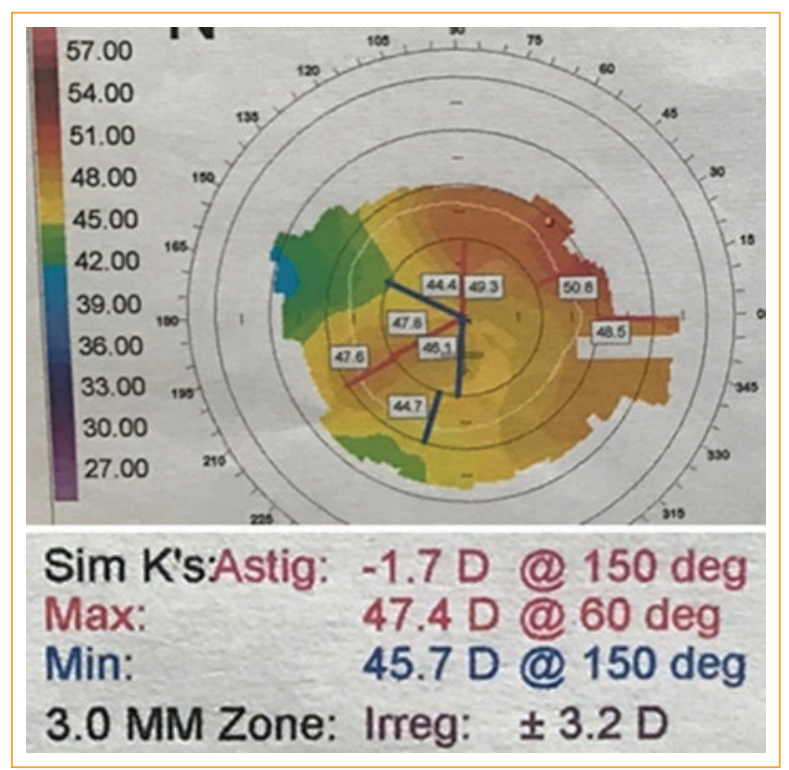

Figure 3. Topografía post-quirúrgica.

20/25 con lentes aéreos, refracción de $-1.25 x-1.50 x$ 170 y un astigmatismo queratométrico de $1.7 \mathrm{D}$ a 150 grados con 3 puntos de sutura aún presentes (Fig. 2). Se obtuvo una reducción del astigmatismo topográfico de $13.3 \mathrm{D}$ (Tabla 1).

\section{Discusión}

El astigmatismo alto residual posqueratoplastia penetrante sigue siendo un reto para el cirujano, que compromete el resultado visual final del paciente. Existen una variedad de tratamientos conservadores, que incluyen lentes aéreos, que pueden generar aniseikonia anisometrópica, y lentes de contacto, que suelen ser poco tolerables. También existen tratamientos quirúrgicos que van desde incisiones relajantes a lentes intraoculares tóricos y técnicas quirúrgicas refractivas con láser, como la queratotomía fotorrefractiva y la queratomileusis in situ con láser, que han probado ser efectivas pero con límites en rango de error refractivo y con complicaciones asociadas, como dehiscencia del injerto y dislocación del flap, que se han reportado hasta en el 9\% de los casos? ${ }^{2}$.
Un gran número de cirujanos han participado en la implementación de técnicas para la reducción del astigmatismo corneal con métodos para aumentar la curvatura corneal, que empezaron con Lans en 1898. Barraquer y Muiños, en 1956, describieron la resección en cuña escleral. También se han descrito técnicas para aplanar la córnea: Snellen, en 1869, sugiere relajantes corneales anteriores, y Sato, en 1950, incisiones relajantes corneales posteriores ${ }^{3}$. Troutman, en 1973, describe la técnica de resección en cuña corneal en conjunto con incisiones relajantes para astigmatismos de más de $10 \mathrm{D}$, y es capaz de corregir del 75 al $80 \%$ de estos errores refractivos. El principio de esta técnica es aumentar la curvatura corneal en el eje más plano mediante la extracción de una cuña y aplanando el eje más curvo mediante las incisiones relajantes corneales para la corrección del astigmatismo'.

Se han observado resultados muy variados en diferentes estudios. Troutman reporta 10 casos, con una corrección astigmática promedio de $7.67 \mathrm{D}$ (3-11.5 D). Krachmer, quien únicamente realiza resección en cuña corneal sin incisiones relajantes corneales, obtiene una corrección astigmática promedio de $6.75 \mathrm{D}(2.75-16.25 \mathrm{D})$ en un reporte de 10 casos con un seguimiento a 16 meses $^{4}$. Hoppenreijs, et al., que reporta 41 casos, logra una corrección astigmática promedio de $8.2 \mathrm{D}(0-16.5 \mathrm{D})$, con un seguimiento a largo plazo de más de 9 años sin incisiones relajantes, quien establece que hay un periodo de estabilidad de 6 meses a 3 años ${ }^{3}$. Ezra, et al., en 2007, combina la resección en cuña con incisiones corneales relajantes y reporta 5 casos con topografía pre y posquirúrgicas por primera vez, y obtiene una corrección astigmática promedio de $12.9 \mathrm{D}$ (6.3-25.4 D), con un seguimiento promedio de 36 meses $(6-96)^{2}$.

En nuestro reporte de caso se combinó la técnica de resección en cuña con incisiones corneales relajantes para la obtención de mayor corrección astigmática, que fue de 13.3 D, que es comparable con el trabajo publicado por Ezra, et al., quien también realiza los dos procedimientos, sin embargo, nuestro seguimiento es a 1 año y tenemos que tener en consideración que nuestro caso aún presenta tres puntos de sutura (Fig. 3) que no han sido retiradas por bajo astigmatismo residual y que las suturas están en el meridiano más curvo, por lo que al retirarlas podríamos esperar una reducción en el astigmatismo o cambio hacia el otro eje. 


\section{Conclusión}

La resección en cuña es un tratamiento efectivo y razonablemente predictivo para astigmatismo posqueratoplastia penetrante y deberá ser considerada como opción de tratamiento. Esta técnica ha demostrado ser útil para astigmatismo residuales altos. Para astigmatismos menores existen otras técnicas menos extensas e invasivas con buenos resultados y reproducibles.

\section{Responsabilidades éticas}

Protección de personas y animales. Los autores declaran que para esta investigación no se han realizado experimentos en seres humanos ni en animales.

Confidencialidad de los datos. Los autores declaran que han seguido los protocolos de su centro de trabajo sobre la publicación de datos de pacientes.
Derecho a la privacidad y consentimiento informado. Los autores han obtenido el consentimiento informado de los pacientes y/o sujetos referidos en el artículo. Este documento obra en poder del autor de correspondencia.

\section{Conflicto de intereses}

Los autores declaran que no existe conflicto de intereses.

\section{Bibliografía}

1. Troutman RC. Corneal Wedge Resections and Relaxing Incisions for Postkeratoplasty Astigmatism Adv. Ophtalmology. Otolaryngol. 1973;77:563.

2. Ezra DG, Hay-Smith G, Mearza A, Falcon MG. Corneal Wedge Excision in the Treatment of High Astigmatism After Penetraiting Keratoplasty. Cornea. 2007;26(7):819-25.

3. Hoppenreijs VP, van Rij G, Beekhuis WH, Rijneveld WJ, Rinkel-van Driel E. Long-term results of corneal wedge resections fo the correction of high astigmatism. Documenta Ophtalmologica. 1990;75:263-73.

4. Krachmer JH, Fenzl RE. Surgical Correction of High Postkeratoplasy Astigmatism. Arch Ophthalmol. 1980;98:1400-2. 